\title{
Degenerative Abnormalities in Transgenic Neocortical Neuropeptide Y Interneurons Expressing Tau-Green Fluorescent Protein
}

\author{
Armelle Rancillac, ${ }^{1 \star}$ Jeanne Lainé, ${ }^{2}$ Quentin Perrenoud, ${ }^{1}$ Hélène Geoffroy, ${ }^{1}$ \\ Isabelle Ferezou, ${ }^{1}$ Tania Vitalis, ${ }^{1}$ and Jean Rossier ${ }^{1}$ \\ ${ }^{1}$ Laboratoire de Neurobiologie, CNRS UMR 7637, ESPCI ParisTech, Paris, France \\ ${ }^{2}$ Laboratoire de Neurobiologie du cervelet, Université Pierre et Marie Curie Paris 6, Faculté de Médecine \\ Pitié Salpétrière, Paris, France
}

The introduction of a reporter gene into bacterial artificial chromosome (BAC) constructs allows a rapid identification of the cell type expressing the gene of interest. Here we used BAC transgenic mice expressing a tau-sapphire green fluorescent protein (GFP) under the transcriptional control of the neuropeptide Y (NPY) genomic sequence to characterize morphological and electrophysiological properties of NPYGFP interneurons of the mouse juvenile primary somatosensory cortex. Electrophysiological whole-cell recordings and biocytin injections were performed to allow the morphological reconstruction of the recorded neurons in three dimensions. Ninety-six recorded NPY-GFP interneurons were compared with 39 wild-type (WT) NPY interneurons, from which 23 and 19 were reconstructed, respectively. We observed that $91 \%$ of the reconstructed NPY-GFP interneurons had developed an atypical axonal swelling from which emerge numerous ramifications. These abnormalities were very heterogeneous in shape and size. They were immunoreactive for the microtubule-associated protein tau and the lysosomal-associated membrane protein 1 (LAMP1). Moreover, an electron microscopic analysis revealed the accumulation of numerous autophagic and lysosomal vacuoles in swollen axons. Morphological analyses of NPY-GFP interneurons also indicated that their somata were smaller, their entire dendritic tree was thickened and presented a restricted spatial distribution in comparison with WT NPY interneurons. Finallly, the morphological defects observed in NPY-GFP interneurons appeared to be associated with alterations of their electrophysiological intrinsic properties. Altogether, these results demonstrate that NPY-GFP interneurons developed dystrophic axonal swellings and severe morphological and electrophysiological defects that could be due to the overexpression of tau-coupled reporter constructs. (๑) 2009 Wiley-Liss, Inc.

Key words: somatosensory cortex; bacterial artificial chromosome; Neurolucida reconstructions; scRT-PCR; patch-clamp; axonal swellings; spheroids; thickenings and tauopathy

$\boldsymbol{\gamma}$-Aminobutyric acid (GABA)-ergic interneurons constitute only a minor fraction of the total number of neurons in the mammalian neocortex (15-25\%; Fairen et al., 1984) but are crucial for normal brain function (McBain and Fisahn, 2001; Whittington and Traub, 2003). Despite their small number, these interneurons are remarkably diverse in their morphological, electrophysiological, and molecular properties (Fairen et al., 1984; DeFelipe, 1993; Cauli et al., 1997; Kawaguchi and Kubota, 1997; Gupta et al., 2000; Markram et al., 2004; Ascoli et al., 2008).

A subclass of these cortical interneurons is indeed characterized by the expression of neuropeptide $\mathrm{Y}$ (NPY), although it presents quite various intrinsic properties (Hendry et al., 1984; Cauli et al., 1997; Karagiannis et al., 2009). NPY expression is therefore likely a property shared by functionally diverse neuronal subpopulations that have just been recently classified into three main types in the rat (Karagiannis et al., 2009).

Here, we were interested in further characterizing this heterogeneous population in the mouse primary somatosensory cortex. For this purpose, we wanted to benefit from the use of transgenic mice selectively expressing the green fluorescent protein (GFP) in NPYexpressing neurons, which cannot otherwise be easily

Additional Supporting Information may be found in the online version of this article.

Contract grant sponsor: French National Research Agency; Contract grant number: ANR-06-NEURO-033-01.

^Correspondence to: Armelle Rancillac, Laboratoire de Neurobiologie, CNRS UMR 7637, ESPCI ParisTech, 10 rue Vauquelin, 75005 Paris, France.

E-mail: armelle.rancillac@espci.fr

Received 15 April 2009; Revised 26 June 2009; Accepted 7 July 2009

Published online 14 October 2009 in Wiley InterScience (www. interscience.wiley.com). DOI: 10.1002/jnr.22234 
identified in an acute slice preparation. This was possible owing to the technology of modified bacterial artificial chromosomes (BACs) used to generate transgenic mice that express green fluorescent protein (GFP) under the control of a cell-specific promoter.

In BACs, large DNA fragments $(>100 \mathrm{~kb})$ are expressed regardless of their site of integration into the genome of the host mice (Giraldo and Montoliu, 2001). The inclusion of marker proteins encoding sequences into endogenous gene loci has not been reported to alter their expression pattern (Miklos and Rubin, 1996; Fritze and Anderson, 2000). Hence, BACs have the advantage of increasing the likelihood of correct temporal and spatial control of gene expression (Heintz, 2001). Thus, this technology allows a specific tagging of neuron subtypes that cannot otherwise be easily identified in an acute slice preparation (Ikawa et al., 1995; Zhuo et al., 1997; Dumitriu et al., 2007).

The use of BAC transgenic mice expressing tausapphire GFP under the transcriptional control of the NPY genomic sequence (Pinto et al., 2004; Roseberry et al., 2004) therefore appeared as a remarkable tool to characterize NPY interneurons from the mouse primary somatosensory cortex. At first sight, the laminar distribution pattern of theses NPY-GFP interneurons seemed comparable to that of NPY interneurons from littermate mice that do not express the BAC construct. Firing patterns and multipolar morphologies of NPY-GFP interneurons grossly appeared in the same range as what was observed in NPY interneurons from wild-type (WT) animals of the same genetic background. However, we were struck by the systematic morphological abnormalities that we found in NPY-GFP interneurons, so we undertook thorough morphological and electrophysiological comparisons, which revealed significant pathological abnormalities in transgenic NPY-GFP interneurons compared with WT NPY interneurons.

\section{MATERIALS AND METHODS}

\section{Animals}

Animals were group housed in a temperature-controlled $\left(21-25^{\circ} \mathrm{C}\right)$ room under daylight conditions and had ad libitum access to food and water. All experiments were carried out in accordance with the guidelines published in the European Communities Council Directive of 24 November 1986 (86/609/ EEC). All efforts were made to minimize the number of animals used and their suffering. The transgenic NPY-GFP mice expressing tau-sapphire GFP under transcriptional control of the NPY genomic sequence (Pinto et al., 2004; Roseberry et al., 2004) were generated by using the BAC transgenic technology developed by Yang and collaborators (1997). In this study, we used male transgenic NPY-GFP mice (a gift from J. Friedman, Rockefeller University, and bred at the Orleans CDTA, France) and male C57Bl/6J mice (Janvier, Le Genest Saint Isle, France).

\section{Immunofluorescence}

Primary antibodies included mouse monoclonal antibodies MAP2 (1:500; Sigma-Aldrich, St. Louis, MO) and tau-1
(1:1,000; Chemicon, Temecula, CA), rat monoclonal Lamp1 $(1: 1,000$; BD Biocsciences, San Jose, CA), and rabbit polyclonal antibodies NPY (1:8,000; Sigma-Aldrich), and GFP (1:800; Invitrogen, Carlsbad, CA). For visualization of neurochemical markers, mice at postnatal day 4 (P4) were anesthetized by hypothermia on ice, whereas older mice (from P18 to 3 months of age) were deeply anesthetized by pentobarbital injections $(50 \mathrm{mg} / \mathrm{kg}$, IP). Animals were perfused through the heart with saline, followed by $4 \%$ paraformaldehyde in $0.1 \mathrm{M}$ phosphate buffer (PB). Fixed brains were dissected out and postfixed overnight at $4^{\circ} \mathrm{C}$. Subsequently, brains were cut into $50-\mu \mathrm{m}$-thick freefloating coronal sections (vibratome VT 1000S Leica), which were immediately processed for immunohistochemistry. Sections were incubated in $10 \%$ goat serum diluted in $0.1 \mathrm{M}$ saline PB (PBS) for $1 \mathrm{hr}$ and then incubated at $4^{\circ} \mathrm{C}$ overnight with primary antibodies diluted in $0.1 \mathrm{M}$ PBS with $0.25 \%$ Triton X-100. They were next rinsed in PBS for $1 \mathrm{hr}$ and incubated with secondary antibodies (Alexa goat anti-rabbit, Alexa goat anti-mouse, or Alexa anti-rat, 1:500; Molecular Probes, Eugene, OR) for $2 \mathrm{hr}$.

After being rinsed in $0.1 \mathrm{M}$ PBS $(3 \times 10 \mathrm{~min})$, sections were incubated $10 \mathrm{~min}$ with Hoechst $(1 \mu \mathrm{g} / \mathrm{ml}$; Sigma $)$ and, after a last wash in 0.1 M PBS, were mounted in Vectashield (Vector Laboratories, Burlingame, CA) on glass slides and coverslipped. Sections were imaged with a Leica confocal SP5 microscope (Plateforme d'Imagerie cellulaire, IFR83, Paris, France). Images were treated and assembled in Adobe Photoshop and Adobe Illustrator CS3.

\section{Preembedding Immunoelectron Microscopy}

Two 40-day-old transgenic NPY-GFP mice and two siblings with no BAC construct expression were deeply anesthetized (pentobartital $60 \mathrm{mg} / \mathrm{kg}$ ) and transcardially perfused with $4 \%$ paraformaldehyde $+0.1 \%$ glutaraldehyde in cold 0.1 $\mathrm{M}$ PB. The dissected neocortex was further postfixed in $4 \%$ paraformaldehyde $+15 \%$ sucrose for $2 \mathrm{hr}$ at $4^{\circ} \mathrm{C}$ and finally cut into $100-\mu \mathrm{m}$-thick coronal sections with a vibratome.

A standard free-floating immunocytochemical procedure was followed, using 0.1 M PBS as diluent and rinsing liquids, with $0.05 \%$ Triton only added to the primary antibody incubation. Briefly, aldehyde quenching in $0.1 \mathrm{M}$ glycine was followed by preincubation in 5\% normal goat serum and overnight incubation at room temperature in rabbit anti-NPY antibody $(1: 15,000)$ or anti-GFP antibody $(1 / 2,000)$.

For immunoperoxidase labelings, a biotinylated antirabbit IgG (Vector Laboratories) was applied as secondary antibody (1/200 in PBS, $2 \mathrm{hr})$, the avidinbiotinylated peroxidase complex (ABC, Vectastain Elite; Vector Laboratories) was used for amplification, and $0.05 \%$ diaminobenzidine was used as the chromogen. For the immunogold procedure, a 4$\mathrm{hr}$ incubation in ultrasmall gold conjugate $\mathrm{F}\left(\mathrm{ab}^{\prime}\right) 2$ fragments of goat anti-rabbit IgG (1/200; Aurion, Amsterdam, The Netherlands) was followed by extensive washings, 10 min postfixation in $2 \%$ glutaraldehyde, and a silver enhancement reaction (NanoProbes), followed by a gold toning procedure.

After $2 \% \mathrm{OsO}_{4}$ postfixation and $2 \%$ uranyl acetate en bloc staining, selected sections were dehydrated in graded acetone and finally embedded in Durcupan (Fluka, Buchs, 
Switzerland) resin. Ultrathin sections were examined with a Philips CM120 electron microscope operated at $80 \mathrm{kV}$ and imaged with a SIS Morada digital camera.

\section{Slice Preparation and Whole-Cell Recordings}

Slices were prepared from P14-P18 transgenic NPYGFP or WT mice. After decapitation, brains were quickly removed and placed into cold $\left(\sim 4^{\circ} \mathrm{C}\right)$ oxygenated artificial cerebrospinal fluid (ACSF) containing (in $\mathrm{mM}$ ): $126 \mathrm{NaCl}$, $2.5 \mathrm{KCl}, 1.25 \mathrm{NaH}_{2} \mathrm{PO}_{4}, 2 \mathrm{CaCl}_{2}, 1 \mathrm{MgCl}_{2}, 26 \mathrm{NaHCO}_{3}$, 10 glucose, 15 sucrose, supplemented with $1 \mathrm{mM}$ of kynurenic acid (nonspecific glutamate receptor antagonist; Sigma). Coronal or parasagittal brain slices $(300 \mu \mathrm{m}$ thick) containing the barrel subfield region of the primary somatosensory cortex were cut with a vibratome (VT1000S; Leica, Nussloch, Germany) and transferred to an incubation chamber containing ACSF saturated with $\mathrm{O}_{2} / \mathrm{CO}_{2}(95 \% / 5 \%)$ at room temperature. After at least $1 \mathrm{hr}$ of incubation, individual slices were transferred to a recording chamber and superfused with oxygenated $30-32^{\circ} \mathrm{C} \mathrm{ACSF}$ (in the absence of kynurenic acid) at a rate of $1-2 \mathrm{ml} / \mathrm{min}$.

Patch pipettes (4-7 M $\Omega$ resistance) pulled from borosilicate glass were filled with $8 \mu \mathrm{l}$ autoclaved internal solution containing (in $\mathrm{mM}$ ): $144 \mathrm{~K}$-gluconate, $3 \mathrm{MgCl}_{2}, 0.5 \mathrm{EGTA}$, 10 HEPES, pH $7.2(285 / 295 \mathrm{mOsm})$, and $2 \mathrm{mg} / \mathrm{ml}$ biocytin (Sigma) for intracellular labeling. Neurons were visualized in the slice by using infrared transmitted light with Dodt gradient contrast optics or epifluorescence illumination, with a Zeiss (Axioskop FX) microscope equipped with a $\times 40$ water immersion objective and a CoolSnap fx CCD camera (Photometrics, Tucson, AZ). Just before breaking of the seal, GFP expression in targeted NPY-GFP cells was rechecked by fluorescence detection. Whole-cell recordings in current-clamp mode were performed with a patch-clamp amplifier (Axopatch 200B; Molecular Devices, Sunnyvale, CA). Data were filtered at $5 \mathrm{kHz}$ and digitized at $50 \mathrm{kHz}$ using an acquisition board (Digidata 1322A; Molecular Devices) attached to a computer running the pCLAMP 9.2 software package (Molecular Devices). All membrane potentials were corrected for liquid junction potential $(-11 \mathrm{mV})$.

\section{Electrophysiological Analysis}

To analyze intrinsic electrophysiological properties of cortical interneurons, 29 electrophysiological parameters (see Supp. Info. Methods) adopting Petilla terminology (Ascoli et al., 2008) were determined for each cell as previously described (Karagiannis et al., 2009) by using custom-written routines running within IgorPro (Wavemetrics, Portland, OR).

\section{Cytoplasm Harvest and Single-Cell Reverse- Transcription Polymerase Chain Reaction}

At the end of the recording, the cytoplasmic content of the cell was aspirated into the recording pipette by application of a gentle negative pressure while maintaining the tight seal. The pipette was then delicately withdrawn to allow outsideout patch formation. The content of the pipette was expelled into a test tube, and reverse transcription (RT) was performed in a final volume of $10 \mu \mathrm{l}$ as previously described (Lambolez et al., 1992). Next, two steps of polymerase chain reaction (PCR) were performed essentially as described previously (Ruano et al., 1995).

The cDNAs present in the $\mathrm{RT}$ reaction were first amplified simultaneously by using the primer pairs designed to amplify cDNAs sequences of the vesicular glutamate transporter 1 (vGlut1); the two isoforms of glutamic acid decarboxylase (GAD65 and GAD67); the three calcium-binding proteins calbindin (CB), calretinin (CR), and parvalbumin (PV); the neuronal isoform of nitric oxide synthase (NOS-1); and the four neuropeptides neuropeptide Y (NPY), somatostatin (SOM), vasoactive intestinal polypeptide (VIP), and cholecystokinin (CCK) as described in Supporting Information Table I. For each primer pair, the sense and antisense primers were positioned on two different exons. GoTaq polymerase (2.5 U; Promega, Madison, WI) and 20 pmol of each primer were added to the buffer supplied by the manufacturer (final volume $100 \mu \mathrm{l}$ ), and 21 cycles $\left(94^{\circ} \mathrm{C}\right.$ for $30 \mathrm{sec}, 60^{\circ} \mathrm{C}$ for $30 \mathrm{sec}$, and $72^{\circ} \mathrm{C}$ for $35 \mathrm{sec}$ ) of PCR were run. Second rounds of PCR were performed using $2 \mu \mathrm{l}$ of the first PCR product as template. In this second round, each cDNA was amplified individually with a second set of primers, internal to the primer pair used in the first PCR (nested primers; see Supp. Info. Table I), and positioned on two different exons. Thirty-five PCR cycles were performed (as described above). Then, $10 \mu \mathrm{l}$ of each individual PCR product was run on a 2\% agarose gel using a 100-base pairs (bp) ladder (Promega) as molecular weight maker and stained with ethidium bromide. The sizes of the PCR-generated fragments were as predicted by the mRNA sequences (see Supp. Info. Table I).

\section{Visualization and Imaging of the Intracellular Biocytin-Filled Neurons}

After the electrophysiological recordings, slices were fixed overnight with $4 \%$ paraformaldehyde in $0.1 \mathrm{M} \mathrm{PB}$ and then stored in PB until subsequent biocytin staining (no longer than 1 week). For brightfield stainings, the slices were washed four times with $0.1 \mathrm{M}$ PBS for $10 \mathrm{~min}$ each. The intrinsic peroxidase activity was blocked by a 30-min incubation of the slices in $3 \% \mathrm{H}_{2} \mathrm{O}_{2}$ diluted in PBS at the last minute. Afterward, the sections were washed four times in 0.1 $\mathrm{M}$ PBS for $10 \mathrm{~min}$ each and permeabilized for $1 \mathrm{hr}$ in $0.2 \%$ Triton X-100 in PBS. Slices were incubated for $2 \mathrm{hr}$ with the ABC peroxidase complex (Vector Laboratories; prepared 30 min in advance) diluted 1:200 in PBS and 1\% Triton X-100 and washed six times in PBS for $10 \mathrm{~min}$ each. For visualization of the stain, the sections were incubated with $0.05 \%$ diaminobenzidine (DAB; Sigma) and $0.01 \% \mathrm{H}_{2} \mathrm{O}_{2}$ in PBS. The reaction was monitored under a dissecting microscope and stopped by rinsing in PBS $(4 \times 10 \mathrm{~min})$ when the cell body and dendritic processes were clearly visible.

\section{Morphological Reconstruction of Recorded Neurons}

To reconstruct the morphology of the recorded neurons, slices were mounted in PBS-glycerol, coverslipped, and sealed with nail polish. Biocytin-filled neurons were visualized, traced, and digitally reconstructed in Neurolucida 
TABLE I. Morphological Somatodendritic Properties of Transgenic and Wild-Type NPY Interneurons ${ }^{\dagger}$

\begin{tabular}{lccc}
\hline & Transgenic $(\mathrm{n}=23)$ & $P$ & Wild type $(\mathrm{n}=19)$ \\
\hline Dendritic tile perimeter $(\mu \mathrm{m})$ & $708.8 \pm 242.9$ & $\star \star \star$ & $1,228.9 \pm 514.2$ \\
Ratio of dendritic length to surface area $\left(\mu \mathrm{m}^{-1}\right)$ & $0.488 \pm 0.087$ & $\star \star \star$ & $0.653 \pm 0.169$ \\
Dendritic tile area $\left(\mu \mathrm{m}^{2}\right)$ & $14,163.0 \pm 7,689.1$ & $\star \star \star$ & $35,336.5 \pm 25,878.0$ \\
Dendritic sholl length at $100 \mu \mathrm{m}(\%)$ & $89.7 \pm 15.0$ & $\star \star$ & $74.1 \pm 19.1$ \\
Dendritic segments length (stdv) $(\mu \mathrm{m})$ & $25.9 \pm 12.0$ & $\star \star$ & $40.2 \pm 19.5$ \\
Cell body perimeter $(\mu \mathrm{m})$ & $39.6 \pm 7.7$ & $\star \star$ & $47.0 \pm 8.8$ \\
Dendritic segments length (mean) $(\mu \mathrm{m})$ & $27.5 \pm 12.2$ & $\star \star$ & $39.5 \pm 15.4$ \\
Cell body area $\left(\mu \mathrm{m}^{2}\right)$ & $103.4 \pm 39.6$ & $\star \star$ & $141.3 \pm 47.5$ \\
Total dendritic length $(\mu \mathrm{m})$ & $1,819.2 \pm 993.6$ & $\star \star$ & $3,032.6 \pm 1,802.4$ \\
Cell body feret min $(\mu \mathrm{m})$ & $9.6 \pm 2.1$ & $\star \star$ & $11.4 \pm 1.913$ \\
Dendritic sholl length at $200 \mu \mathrm{m}(\%)$ & $9.2 \pm 13.8$ & $\star$ & $19.9 \pm 13.1$ \\
Cell body feret max $(\mu \mathrm{m})$ & $14.0 \pm 3.0$ & $\star$ & $16.6 \pm 3.6$ \\
Dendritic planar angle $(\mathrm{average})($ degrees) & $51.0 \pm 6.4$ & $\star$ & $47.0 \pm 4.1$ \\
Dendritic sholl length at $300 \mu \mathrm{m}(\%)$ & $1.1 \pm 2.3$ & $\star$ & $4.8 \pm 7.4$ \\
Dendritic sholl length at $400 \mu \mathrm{m}(\%)$ & $0.0 \pm 0.0$ & $\star$ & $1.2 \pm 2.7$ \\
\hline
\end{tabular}

${ }^{\dagger}$ Values are means \pm standard deviations. Significant differences were determined by using a $t$-test. Parameters not statistically different are shown in Supporting Information Table II.

$\star$ Significantly superior at $P=0.05$.

$\star \star$ Significantly superior at $P=0.01$.

$\star \star \star$ Significantly superior at $P=0.001$.

software (MicroBrightField, Bioscience Europe, Magdeburg, Germany) with a $\times 100$ oil-immersion objective (Leica). Drawn neurons were rated on 53 somatodendritic morphological parameters using the analytic tools in NeuroExplorer (see Table I and Supp. Info. Table II). We did not discriminate on chosen parameters but rather tried to describe each neuron in as much depth as the program allowed.

\section{RESULTS}

To study the morphological and electrophysiological properties of NPY interneurons in the mouse primary somatosensory cortex, we used transgenic NPYGFP mice expressing tau-sapphire GFP under transcriptional control of the NPY genomic sequence (Pinto et al., 2004; Roseberry et al., 2004). Data collected from NPY-GFP interneurons were compared with those collected from WT NPY interneurons of the same genetic background.

\section{NPY-GFP-Expressing Interneurons in the Somatosensory Cortex}

To investigate the accuracy of the transgene expression at the cellular level, we performed NPY immunofluorescent labeling on the primary somatosensory cortex of fixed brain sections and observed the endogenous fluorescence of the GFP. There was a good correlation between NPY and GFP expression (Fig. 1). Colocalization studies indicated that approximatively $84 \%(\mathrm{n}=138)$ of GFP-positive cell bodies were NPY immunoreactive (-IR), whereas $80 \%(\mathrm{n}=145)$ of NPY-IR neurons expressed GFP. The lack of $100 \%$ overlap could be due to NPY levels under the detection limits of the immunostaining or, alternatively, could arise from the low levels of GFP expression, as we observed its endogenous fluorescence.
A qualitative examination of the laminar distribution pattern of NPY-GFP interneurons in the mouse primary somatosensory cortex revealed that these interneurons were present in all layers, with a greater density in layers II/III and VI (Supp. Info. Fig. 1A). A similar NPY expression pattern has been previously observed in the rat cerebral cortex (Hendry et al., 1984; Kubota et al., 1994).

\section{Morphological Properties of NPY-GFP and WT NPY Interneurons}

The green fluorescence of NPY-GFP interneurons was sufficiently bright to perform targeted patch-clamp recordings using epifluorescence in combination with infrared microscopy (Fig. 2C,D), within the primary somatosensory cortex of juvenile transgenic mice (P14$21, \mathrm{n}=22$ mice). Whole-cell current-clamp recordings were performed with biocytin-containing pipettes to allow a post hoc morphological identification and reconstruction in three dimensions. Ninety-six NPY-GFP biocytin-filled interneurons were recovered after fixing the slices. Among these 96 recorded interneurons, 32 were well labeled and 23 were reconstructed in the Neurolucida software (Fig. 2A) to analyze their morphological features. Unreconstructed interneurons were either too deep into the slice to focus properly on the cell, or too superficial, presenting truncated processes.

Surprisingly, we observed in these neurons axonal swellings from which emerged numerous ramifications. These abnormalities were very heterogeneous in shape and size and could even be confused with a neuronal soma (Fig. 2A,E). Generally, a neuron was found to be associated with a single swelling. In only 9\% (2 of 23) of the reconstructed NPY-GFP interneurons, such thickenings were not observed. 

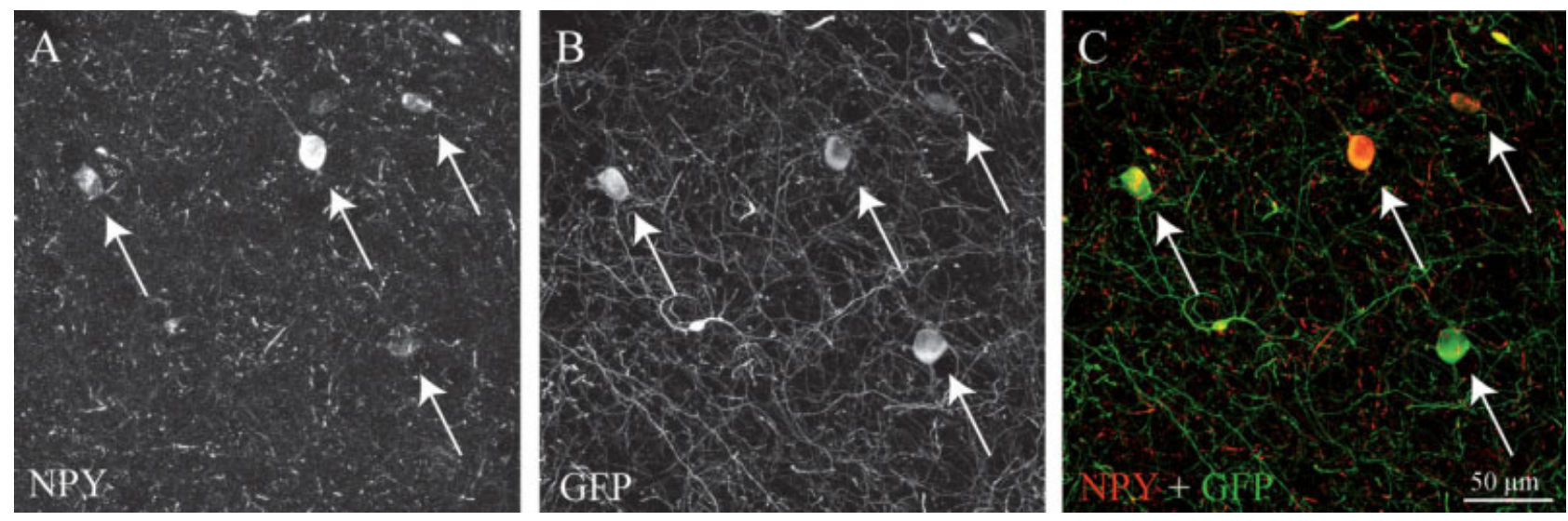

Fig. 1. NPY immunolabelling of GFP-NPY transgenic mouse primary somatosensory cortex confirms the specific expression of GFP in NPY interneurons. Confocal reconstructions consisted of a z-series of 17 images, projected in one layer via the maximum of intensity method (the spacing of successive z-images was $1 \mu \mathrm{m}$ ). A: Arrows point to NPY-immunoreactive neurons. B: Arrows indicate neurons that express GFP, as indicated by their green fluorescence. C: Arrows designate neurons that coexpress NPY (red, seen in A) and GFP (green, seen in B). [Color figure can be viewed in the online issue, which is available at www.interscience.wiley.com.]
Electrophysiological recordings were also performed on WT NPY interneurons together with biocytin staining to compare 3-D reconstructions of transgenic vs. WT NPY interneurons. Because there are no distinctive features to target WT NPY-expressing neurons specifically under infrared illumination, the recorded interneurons were subsequently analyzed by single-cell reverse-transcription polymerase chain reaction (scRTPCR; Fig. 2B). The scRT-PCR protocol was designed to detect the expression of mRNAs encoding for the vesicular glutamate transporter (vGlut1); the GABA-synthesizing enzymes GAD65 and GAD67; the calciumbinding proteins $\mathrm{CB}, \mathrm{CR}$, and $\mathrm{PV}$; the neuronal isoform of the nitric oxyde synthase (NOS-1); and the neuropeptides NPY, SOM, VIP, and CCK. This molecular analysis revealed the expression of NPY in 39 electrophysiologically recorded and biocytin-labeled WT interneurons, among which 19 were reconstructed (Fig. 2A). In contrast to NPY-GFP interneurons, WT NPY interneurons presented a normal axonal morphology without any apparent swelling.

We further compared the somatodendritic morphological properties of NPY-GFP interneurons vs. WT NPY interneurons. Eleven somatic and 42 dendritic variables were chosen, among which 15 were significantly different (Table I; parameters that were not significantly different are shown in Supp. Info. Table II). The most striking differences were related to the tiling analysis, which was performed on the two-dimensional projection of the neurons to contour their dendritic arborization. The dendritic tile perimeter and area were smaller for NPY-GFP interneurons than for WT NPY interneurons (709 \pm 243 vs. $1,229 \pm 514 \mu \mathrm{m}, P<0.001$ and 14.163 $\pm 7,689$ vs. $35,337 \pm 25,878 \mu^{2}, P<0.001$, respectively), suggesting that transgenic NPY-GFP interneurons presented a restricted dendritic arborization in com- parison with WT NPY interneurons. Indeed, although NPY-GFP interneurons had similar average numbers of primary dendrites $(8.5 \pm 3.1$ vs. $7.7 \pm 3.6$, respectively), they presented a smaller dendritic extent than WT NPY interneurons. The total dendritic length and the average and the standard deviation segments length were statistically smaller in the NPY-GFP interneurons $(1,819.2 \pm$ 993.6 vs. $3,032.6 \pm 1802.4, P<0.01 ; 27.5 \pm 12.2$ vs. $39.5 \pm 15.4 \mu \mathrm{m}, P<0.01$ and $25.9 \pm 12.0$ vs. $40.2 \pm$ $19.5 \mu \mathrm{m}, P<0.01$, respectively). Therefore, parameters directly linked to the dendritic length were also significantly smaller, as were the dendritic Sholl (defined as the percentage of dendritic length included in $100 \mu \mathrm{m}$ concentric circles) at $100 \mu \mathrm{m}(89.7 \pm 15.0$ vs. $74.1 \pm$ $19.1 \%$, respectively; $P<0.01), 200 \mu \mathrm{m}(9.2 \pm 13.8$ vs. $19.9 \pm 13.1 \%$, respectively; $P<0.05), 300 \mu \mathrm{m}(1.1 \pm$ 2.3 vs. $4.8 \pm 7.4 \%$, respectively; $P<0.05)$ and $400 \mu \mathrm{m}$ $(0.0 \pm 0.0$ vs. $1.2 \pm 2.7 \%$, respectively; $P<0.05)$. On the other hand, the total dendritic volume and surface were not significantly different between the NPY-GFP interneurons and the WT interneurons $(745.0 \pm 550.8$ vs. $859.9 \pm 614.5 \mu^{3}$ and $3,919.5 \pm 2,430.2$ vs. $4,903.4 \pm 2,976.0 \mathrm{~mm}^{2}$, respectively), suggesting that the entire transgenic dendritic tree was thickened. Finally, the dendritic arborization of the transgenic NPY-GFP interneurons presented an average planar angle (the angular value between two dendrites) that was significantly larger $(51.0 \pm 6.4$ vs. $47.0 \pm 4.1$, respectively; $P<0.05$ )

At the somatic level, it also appeared that NPYGFP interneurons were significantly smaller than WT NPY interneurons. Indeed, their somatic perimeter, area, and feret min and max (the largest and smallest dimensions of the soma) were significantly smaller (39.6 \pm 7.7 vs. $47.0 \pm 8.8 \mu \mathrm{m}, P<0.01 ; 103.4 \pm 39.6$ vs. $141.3 \pm 47.5 \mu^{2}, P<0.01 ; 9.6 \pm 2.1$ vs. $11.4 \pm$ 
A
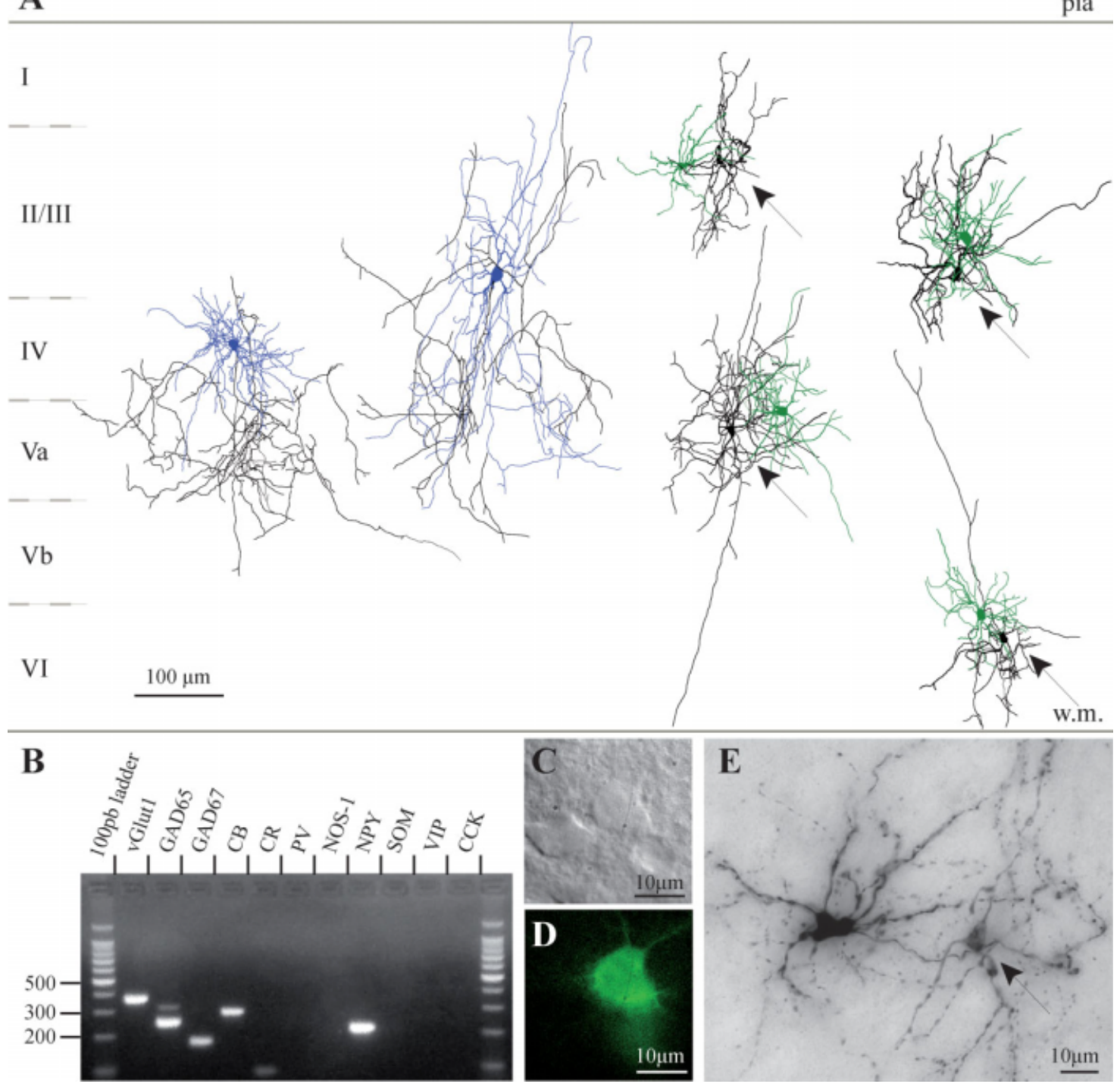

Fig. 2. Anatomical reconstructions of WT NPY and NPY-GFP interneurons. A: Interneurons were injected with biocytin during electrophysiological recordings to allow their post hoc identification and three-dimensional morphological reconstruction. Representative examples of interneurons from WT and transgenic mice are shown. Axons are in black, whereas somata and dendrites are color coded: blue for WT NPY interneurons and green for NPY-GFP interneurons. Cortical layer boundaries are marked with bars. Arrows indicate axonal swellings. B: scRT-PCR products of the WT NPY interneuron shown in A in layer II/III were resolved in separate lanes by agarose gel electrophoresis in parallel with a 100-bp ladder as molecular weight marker and stained with ethidium bromide. The ampli-

$1.9 \mu \mathrm{m}, P<0.01$; and $14.0 \pm 3.0$ vs. $16.6 \pm 3.6 \mu \mathrm{m}$, $P<0.05$; respectively). Altogether, these results outline important morphological differences between transgenic NPY-GFP interneurons and WT NPY interneurons at the axonal, dendritic, and even somatic levels. fied fragments had the sizes (in bp) predicted by the mRNA sequences: 367 (vGlut1), 248 (GAD65), 177 (GAD67), 295 (CB), and 220 (NPY). C,D: Before patch-clamp recordings of NPY-GFP interneurons, a microphotograph of the cell body was taken by using infrared microscopy (C) and epifluorescence (D). These are microphotographs of the most superficial NPY-GFP reconstructed interneuron shown in A. E: Light microphotograph of the same neuron after biocytin injection, fixation of the slice, and histochemical revelation with the $\mathrm{ABC}-\mathrm{DAB}$ staining method. The arrow indicates a swelling. [Color figure can be viewed in the online issue, which is available at www.interscience.wiley.com.]

\section{Characterization of NPY-GFP Interneuron Swellings by Immunofluorescence}

Confocal scan images of NPY or GFP immunostaining also confirmed abnormal swellings and ramifications of NPY interneurons from transgenic brain sections (Fig. 3) but not in brain sections from littermate mice 

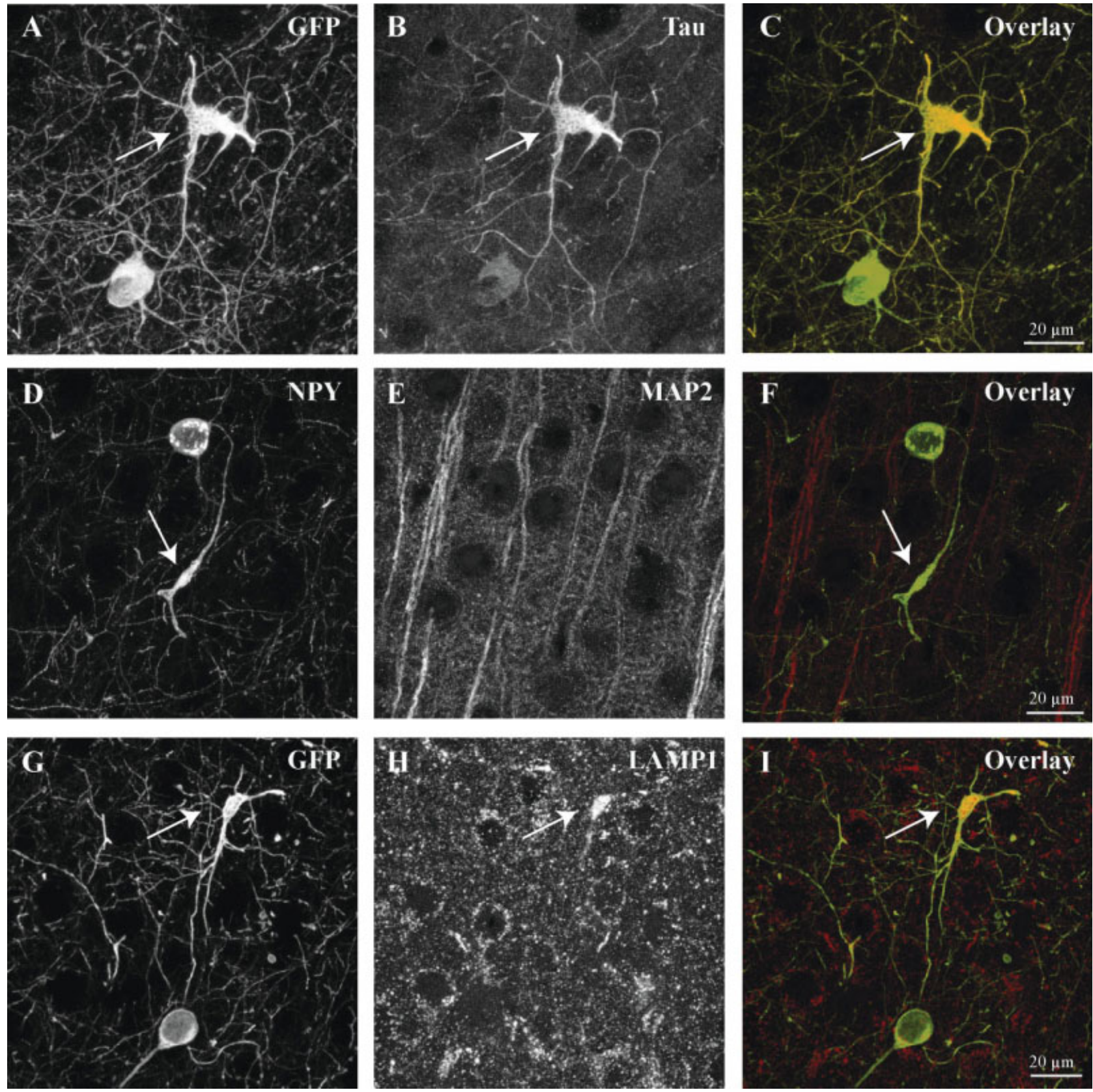

Fig. 3. NPY-GFP interneurons swellings are axonal and contain numerous lysosomes. Arrows point toward swellings. A-C: Confocal reconstructions consisted of a z-series of 13 images, projected in one layer via the maximum of intensity method (the spacing of successive $z$-images was $1 \mu \mathrm{m}$ ). The immunostaining anti-GFP (A) and anti-tau (B) are pseudocolored in green and red, respectively, in C. Colocalization of the two labels is revealed by the yellow color in $\mathrm{C}$, indicating that the swelling is localized on the axon. D-F: Confocal reconstructions consisted of a $z$-series of four images, projected in one layer via the maximum of intensity method (spacing of successive $z-$ images was $1 \mu \mathrm{m})$. The immunostainings with anti-NPY (D) and

with no expression of the BAC construct (data not shown). With NPY-GFP brain sections, we carried out double labeling for GFP and the microtubule-associated
anti-MAP2 (E) are pseudocolored in green and red, respectively, in F. Swellings immunoreactive for NPY never display MAP2 immunostaining, indicating that they are not localized on a dendrite. G-I: Confocal reconstructions consisted of a z-series of eight images, projected in one layer via the maximum of intensity method (spacing of successive $z$-images was $1 \mu \mathrm{m})$. The staining anti-GFP $(G)$ and antiLAMP1 $(\mathrm{H})$ are pseudocolored in green and red, respectively, in I. The yellow seen in I indicates colocalization of the two labels, notably intense within the axonal swelling. [Color figure can be viewed in the online issue, which is available at www.interscience.wiley. com.]

protein tau, which is enriched in the axonal compartment (Fig. 3A-C). All GFP-IR swellings were also tauIR, indicating that these anomalies were located at the 
axonal level, as predicted by the observation of biocytinstained neurons. In our BAC transgenic construction, the GFP protein is fused with tau and is therefore addressed only to axons. To examine whether swellings could also be localized at the dendritic level, we next performed a double immunolabeling of the NPY and of the cytoskeletal protein MAP2, which is specifically expressed in dendrites (Fig. 3D-F). Indeed, it has already been shown that NPY-positive neurons of the rat cerebral cortex are homogenously labeled at the axonal and somatodendritic levels (Hendry et al., 1984). We did not observe any NPY-MAP2 immunoreactive swellings. Together, these results indicate a clear axonal localization of the swellings.

Furthermore, because numerous double-membrane vesicle accumulation in such swollen axons has already been observed during neurodegeneration (Wang et al., 2006), we performed double immunostaining against GFP and the lysosomal-associated membrane protein 1 (LAMP1). This treatment revealed a strong density of lysosomes in the center of the large swellings. Note that most of the sapphire was found in the vicinity of lysosomes, but not in the vesicular lumen (Fig. 3G-I). These results suggest that, in transgenic NPY-GFP interneurons, a lysosome accumulation causes the formation of axonal swellings.

To investigate whether thickenings were already developed in younger animals, we performed NPY immunolabeling at P4 and compared NPY interneuron morphologies from GFP-expressing transgenic mice and their littermates that do not express the BAC. In newborn animals, the laminar density and morphology of NPY-IR neurons in the cerebral cortex were different from those of juveniles, because these neurons mature postnatally (Antonopoulos et al., 1992). NPY-IR at P4 revealed no differences between transgenic NPY-GFP interneurons and littermates NPY interneurons (Fig. 4A,B). However, later, at P18, we already observed large morphological abnormalities (Fig. 4C-E), suggesting that swellings probably result from a time-dependent accumulative process. However, these aberrations were virtually the same in complexity and density in 3-month-old transgenic mice (data not shown). Finally, these swellings were observed through the entire cortex and hippocampus (Supp. Info. Fig. 1) but not in subcortical regions such as the hypothalamus (data not shown).

\section{Characterization of NPY-GFP Axonal Swellings by Electron Microscopy}

Preembedding immunolabelings with anti-NPY or anti-GFP antibodies were used to identify NPY-positive somata and neurites in 40-day-old mouse primary somatosensory cortex from GFP-expressing transgenic animals and BAC construct-free littermate animals. The NPYtagged elements were further examined at the ultrastructural level. In NPY-GFP transgenic mice, no gross abnormalities were detected at the level of NPY soma or dendrite profiles; in particular, no nuclear alterations
GFP+
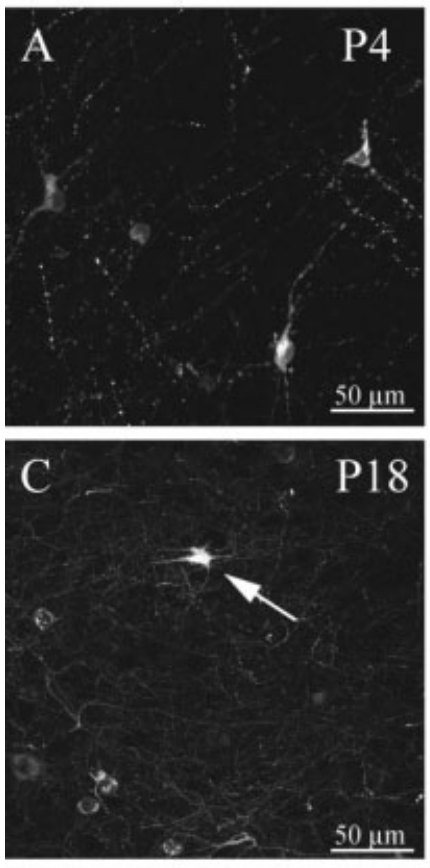

P18

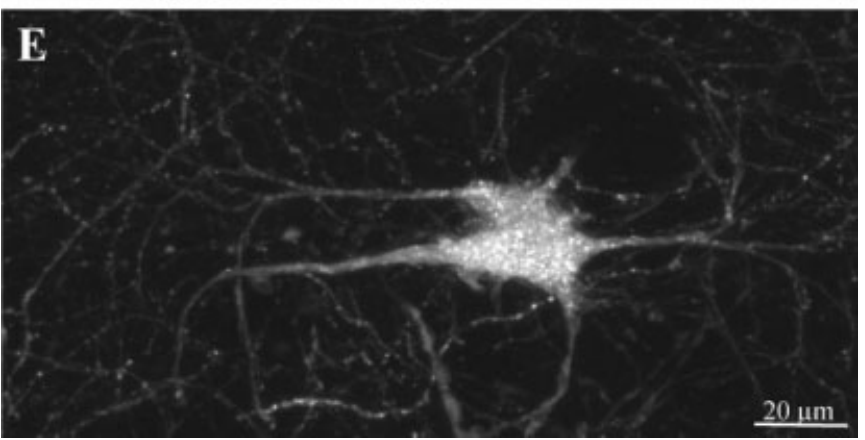

Fig. 4. NPY immunostainings show that NPY-GFP interneurons develop swellings progressively as the mice get older. A,B: Sections from a 4-day-old NPY-GFP transgenic mouse $\left(\mathrm{GFP}^{+}, \mathrm{A}\right)$ and from its sibling, which do not express the BAC construct $\left(\mathrm{GFP}^{-}, \mathrm{B}\right)$, reveal similar morphologies of NPY-immunoreactive neurons. Confocal reconstructions consisted of a z-series of 18 images, projected in one layer via the maximum of intensity method (spacing of successive z-images was $1 \mu \mathrm{m})$. C,D: At P18, we observed morphological abnormalities (arrow) in NPY interneurons from NPY-GFP transgenic mouse (C), which were absent in a littermate $\mathrm{GFP}^{-}$mouse (D). Confocal reconstructions consisted of a z-series of 16 images, projected in one layer via the maximum of intensity method (spaced by $0.8 \mu \mathrm{m})$. E: The morphological abnormality indicated in $\mathrm{C}$ by the arrow shown at a higher magnification.

were present. In contrast, all the heavily labeled, swollen neurite portions detected by their NPY (not illustrated) or GFP labeling (Fig. 5B) exhibited a similar content. These swollen profiles were invariably filled with an accumulation of various kinds of rimmed or unrimmed vacuoles, as illustrated in the Figure 5. Some vacuoles with a double limiting membrane appeared to be auto- 

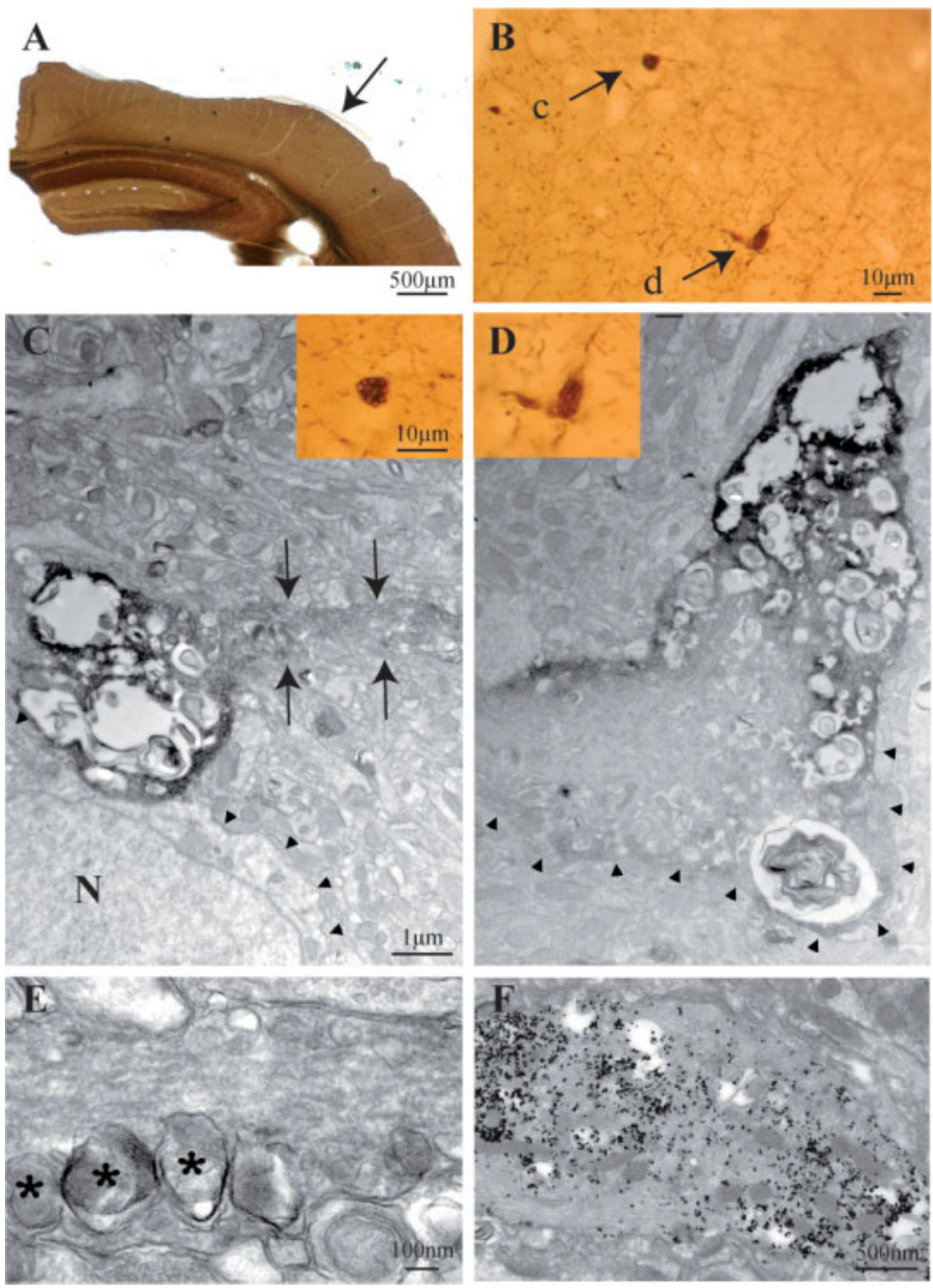

Fig. 5. Ultrastructural features of representative swellings located on NPY-GFP axons, as identified by anti-GFP immunolabeling. A: Low-magnification micrograph indicating the somatosensory cortex location of the two abnormal axonal swellings illustrated in C,D. B: The two GFP-peroxidase-labelled thickenings are indicated by arrows. C,D: High-power photonic and electron micrographs of the two swellings. The inset in $\mathrm{C}$ shows a heavily labelled spherical structure with a spongy aspect. At the ultrastructural level (C), this spherical structure appears strongly GFP-labelled and contains mainly giant electrolucent vacuoles and membrane whorls. It is in close contact with a neuronal soma ( $\mathrm{N}$, arrowheads outline its plasmalemma), and a more faintly labelled stalk emerges from it (arrows), which contains smaller degradative vacuoles (see E). In the photonic view of the inset in D, the axonal swelling appears elliptical, with two branches emerging at right angles, indicating that it is not an end-

bulb. The electron micrograph in $\mathrm{D}$ shows the same degenerative features as in C, with more or less voluminous stacked vacuoles, either "empty" or containing pseudomyelinic membranes. Arrowheads indicate its lower outline. As in C, the GFP labelling is heavier in the more degenerative portions of the neurite. E: High magnification of the faintly GFP-labelled stalk emerging from the spheroid illustrated in C, at four sections farther away. Well-aligned microtubules, somewhat thickened by immunoperoxidase precipitate diffusion, adjoin autophagic vacuoles (asterisks) that lie just under the axolemma. F: A GFP-gold-labelled axonal swelling. In its lower part, microtubules appear regularly disposed, whereas, in the two zones where silver-gold beads are densely packed and electrolucent, degenerative vacuoles are present, the microtubules appear disorganized. [Color figure can be viewed in the online issue, which is available at www.interscience.wiley.com.] 
TABLE II. Electrophysiological Properties of Transgenic and Wild-Type NPY Interneurons ${ }^{\dagger}$

\begin{tabular}{lccc}
\hline & Transgenic $(\mathrm{n}=96)$ & $P$ & Wild type (n = 39) \\
\hline (11) Amplitude of early adaptation $(\mathrm{Hz})$ & $174.42 \pm 66.89$ & $\star \star \star$ & $90.56 \pm 58.17$ \\
(3) Membrane time constant (msec) & $12.17 \pm 6.90$ & $\star \star \star$ & $27.91 \pm 23.59$ \\
(2) Input resistance $(\mathrm{M} \Omega)$ & $246.66 \pm 77.44$ & $\star \star \star$ & $419.22 \pm 272.47$ \\
(12) Time constant of early adaptation (msec) & $17.42 \pm 6.22$ & $\star \star \star$ & $24.48 \pm 11.76$ \\
(4) Membrane capacitance (pF) & $50.55 \pm 23.34$ & $\star \star \star$ & $74.02 \pm 39.58$ \\
(17) First spike duration (msec) & $0.64 \pm 0.15$ & $\star \star \star$ & $0.76 \pm 0.22$ \\
(15) LTS & $0.00 \pm 0.00$ & $\star \star$ & $0.10 \pm 0.31$ \\
(23) Second spike duration (msec) & $0.68 \pm 0.17$ & $\star \star$ & $0.80 \pm 0.24$ \\
(5) Sag index (\%) & $16.07 \pm 8.14$ & $\star \star$ & $11.52 \pm 6.75$ \\
(16) First spike amplitude (mV) & $86.01 \pm 9.44$ & $\star \star$ & $80.72 \pm 9.21$ \\
(9) Minimal steady state frequency (Hz) & $6.18 \pm 3.57$ & $\star \star$ & $8.20 \pm 3.76$ \\
(22) Second spike amplitude (mV) & $84.01 \pm 9.25$ & $\star \star$ & $78.94 \pm 9.56$ \\
(14) Maximal steady state frequency (Hz) & $83.13 \pm 23.85$ & $\star$ & $97.18 \pm 40.35$ \\
(1) Resting membrane potential (mV) & $-72.73 \pm 4.55$ & $\star$ & $-75.23 \pm 6.87$ \\
(6) Rheobase (pA) & $114.90 \pm 98.38$ & $\star$ & $74.87 \pm 80.39$ \\
\hline
\end{tabular}

${ }^{\dagger}$ Values are means \pm standard deviations. Statistically significant differences were determined by using a $t$-test. Electrophysiologycal parameters were measured as described in Supporting Information Methods. Parameters not statistically different are shown in Supporting Information Table III.

$\star$ Significantly superior at $P=0.05$.

$\star \star$ Significantly superior at $P=0.01$.

$\star \star \star$ Significantly superior at $P=0.001$.

phagosomes (Fig. 5E), whereas others containing electrodense or multilamellar material showed lysosome characteristics. Some larger vacuoles appeared "empty," with a completely electrolucent appearance, just edged by some membranous fragments, and could be residual bodies derived from lysosomes (Fig. 5C,D). When branches stemming from these swellings were present in the same ultrafine section, they were filled with stacked microtubules (Fig. 5E), which could adjoin autophagic vacuoles. No synapses were observed on these dystrophic profiles, confirming their axonal quality. Notably, in contrast to the less dystrophic parts, where the immunostaining was moderate, a strong GFP-peroxidase or -gold marking was systematically present nearby and within the highly degenerated portions of the axon, suggesting an accumulation of tau-GFP protein (Fig. 5C,D,F).

\section{Electrophysiological Properties of NPY-GFP and WT NPY Interneurons}

The geometry of a neuron is causal for the electrical excitability measured at a soma (Mainen and Sejnowski, 1996; Schaefer et al., 2003). Increasing evidence from computational studies suggests that dendritic morphology can robustly affect electrotonic characteristics (Carnevale et al., 1997), firing pattern (Krichmar et al., 2002), synaptic integration (Poirazi et al., 2003), and coincidence detection properties of a given neuron (Schaefer et al., 2003).

Because NPY-GFP interneurons displayed abnormal morphologies compared with NPY interneurons from mice with no BAC expression, we wondered whether other differences also occurred for their electrophysiological properties. Therefore, we compared the electrophysiological properties of 96 cortical NPY-GFP interneurons vs. 39 WT NPY interneurons of the primary somatosensory cortex. The proportion of NPYexpressing interneuron subtypes depends on their location within the depth of the cortex. For example, in the rat somatosensory cortex, fast spiking cells are absent from layer I (Karagiannis et al., 2009). Therefore, caution was taken to record NPY-expressing interneurons from comparable depths $(2.96 \pm 1.58$ for transgenic and $2.64 \pm 1.36$ for WT NPY interneurons).

To take into account the electrophysiological diversity of these interneurons (Karagiannis et al., 2009), 29 electrophysiological features were determined for each cell (see Materials and Methods), among which 15 were significantly different (Table II; parameters that were not significantly different are shown in Supp. Info. Table III). In comparison with WT NPY interneurons, NPY-GFP interneurons were characterized by a lower membrane capacitance $(50.5 \pm 23.3$ vs. $74.0 \pm 39.6 \mathrm{pF}$, $P<0.001$, respectively) and a higher amplitude and lower time constant of early frequency adaptation (174.4 \pm 66.9 vs. $90.6 \pm 58.2 \mathrm{~Hz}, P<0.001$; and $17.4 \pm 6.2$ vs. $24.5 \pm 11.8 \mathrm{msec}, P<0.001$, respectively). Recorded transgenic NPY-GFP interneurons appeared to be electrically less excitable than nontransgenic interneurons insofar as they displayed a lower input resistance $(246.7 \pm 77.4$ vs. $419.2 \pm 272.5 \mathrm{M} \Omega$, respectively; $P<$ $0.001)$ and a shorter membrane time constant (12.2 \pm 6.9 vs. $27.9 \pm 23.6 \mathrm{msec}$, respectively; $P<0.001$ ). Other distinctive features of these NPY-GFP interneurons consisted of the observation of pronounced voltage sag induced by hyperpolarized current pulses (16.1 \pm 8.1 vs. $11.5 \pm 6.7 \%$, respectively; $P<0.01)$ and the absence of LTS. This suggests that the distribution of transmembrane conductances along the neuronal membrane was also modified in these transgenic interneurons, inso- 
far as the pattern of $\mathrm{Ca}^{2+}$ channels distribution influences the LTS response of a cell (Zomorrodi et al., 2008). Finally, these NPY-GFP interneurons fired action potentials of higher amplitudes $(86.0 \pm 9.4$ vs. $80.7 \pm$ $9.2 \mathrm{mV}$, respectively, for the first spike; $P<0.01$ ) and shorter durations $(0.6 \pm 0.2$ vs. $0.8 \pm 0.2 \mathrm{mV}$, respectively, for the first spike; $P<0.01$ ). Altogether, these results strongly suggest that transgenic NPY-GFP interneurons are morphologically and electrophysiologically quite different from WT NPY interneurons.

\section{DISCUSSION}

This study, originally aimed at thoroughly characterizing mouse NPY neocortical interneurons, finally turned to describing the damaging consequences of the BAC transgenic construct expressing a tau-sapphire GFP reporter gene under transcriptional control of the NPY genomic sequence. Indeed, our results show altered morphological and electrophysiological properties of interneurons expressing the transgene in comparison with WT NPY interneurons. The BAC expression was associated with abnormal axonal dystrophic swellings, together with a global thickening of the dendrites. NPYGFP interneurons also presented a restricted spatial extent of their dendritic tree and a smaller soma than WT NPY interneurons. Finally, the morphological defects observed in NPY-GFP interneurons appeared to be associated with alterations of their electrophysiological intrinsic properties.

\section{BACs: Interest and Disadvantages}

BACs have been used extensively for mouse transgenesis (Heintz, 2001; Giraldo et al., 2003; Heaney and Bronson, 2006). The introduction of reporter genes into the BAC construct allows the rapid and precise identification of the cell types that express the gene of interest. Because of their large insert size, they can also contain long-range cis-regulatory elements of the gene of interest, required for correct tissue-specific or temporal expression. Therefore, BAC insertions are thought to be more resistant to positional effects than smaller transgenes (Giraldo and Montoliu, 2001; Gong et al., 2003). Finallly, BAC constructs are stable and reproducibly expressed (Shizuya et al., 1992).

However, despite these numerous advantages, BAC technology also presents some drawbacks. First, random transgene insertion into the mouse genome could induce the generation of phenotypes caused by the site of integration. During random integration, it is possible for a transgene to insert into either the coding or the regulatory sequence of an endogenous gene, resulting in the disruption or alteration of this gene expression (Krulewski et al., 1989; Ross et al., 1998; Rachel et al., 2002). Generally, insertional effects on another gene will not result in an unexpected phenotype, because only one allele integrates BACs. However, if this modification results in haploinsufficiency, or if the transgene is bred to homozygoty, a phenotype resulting from the disruption of an endogenous gene may be observed.

On the other hand, transgenic mice that carry a properly engineered BAC construct often contain multiple copies of a BAC, and its overproduction might have phenotypic consequences (Heintz, 2001). It has been suggested that BACs typically incorporate as one- to five-copy concatamers within a single locus of the genome (Jaenisch, 1988; Giraldo and Montoliu, 2001; Heaney and Bronson, 2006). Chandler et al. (2007) even reported that $50 \%$ of their transgenic lines had approximately 48 or more copies. For BAC transgenes containing the elements necessary to confer position-independent expression, a linear relationship between copy number and gene expression is generally observed (Chandler et al., 2007). However, in rare instances, in which many (eight or more) copies of a large transgene integrate into the genome, the linear relationship between copy number and expression level is lost as a result of transgene silencing (Henikoff, 1998; Heaney and Bronson, 2006). Anyway, the morphological and electrophysiological alterations observed in this study could be phenotypic consequences of our BAC transgene overproduction and thus potentially relay on an excessive production of the tau-GFP fusion protein.

\section{Tau-Sapphire GFP Overexpression Could Compromise Lysosomal Function}

GFP from the jellyfish Aequorea victoria and more recently the novel GFP-like proteins from Anthozoans (coral animals; Chudakov et al., 2005) have greatly advanced our technologies for fluorescently labeling cells. However, overexpression of such fluorescent proteins can induce electrostatic or hydrophobic interactions between GFP-like proteins that might result in the formation of aggregates (Katayama et al., 2008). This phenomenon is likely to alter the functions of lysosomes and autophagosomes, which are important in preventing the accumulation of damaging aggregated proteins (Nixon, 2006; Rubinsztein, 2006). Compromised function of lysosomes and other degradative organelles that interact with the lysosomal pathway are strongly implicated in neurodegenerative disease pathology (Nixon and Cataldo, 2006; Rubinsztein, 2006). Indeed, an increased number of enlarged lysosomes has been observed in affected neurons of Alzheimer's disease human brains (Cataldo et al., 1996). Axonal swellings, or spheroids, are a hallmark of CNS axon degeneration during aging and in many disorders, although their direct cause and underlying mechanisms are still unknown.

High levels of fluorescent protein expression in cortical neuronal cultures have been shown to result in loss of neurites and apoptotic induction (Detrait et al., 2002), and, similary, it has been reported that coexpression of enhanced GFP with $\beta$-galactosidase in mouse forebrain neurons induces growth retardation and premature cell death (Krestel et al., 2004). Moreover, high-level expression of a yellow fluorescent protein (YFP), a color variant 
of Aequorea GFP, leads to an increase in age-related axonal swelling and with accumulation of degenerated membrane bound organelles (Bridge et al., 2009).

On the other hand, Katayama and coworkers (2008) have shown that transfection of sapphire into mammalian cells did not result in the formation of any visible precipitates after 1 week and that sapphire is degraded in lysosomes. These results are consistent with our results at $\mathrm{P} 4$, in which no precipitates nor any swellings were observed. Later, at P18, GFP immunostaining did not show either any precipitates or any colocalization of sapphire with Lamp-1. Moreover, GFP immunoelectron microscopy at P40 showed that, if sapphire accumulates within the axonal swellings, it does not appear to saturate the lysosomal profiles. Together, these results suggest that excess sapphire is probably targeted by autophagy to lysosomes, where it is degraded (Klionsky and Emr, 2000; Mizushima et al., 2002).

\section{Fusion of Sapphire GFP With Tau Could Induce Cytoskeleton Deleterious Interactions}

Generation of the fusion protein tau-GFP has been developed to target GFP to axonal microtubules and therefore enhance the cellular distribution of GFP by improving the visualization of neuronal distal axonal structures (Brand, 1995). Although reporter genes are routinely used, there are concerns that their expression could disrupt the development and structure of neurons. Observations of swellings and axon degeneration are also seen when tau is overexpressed in mouse CNS neurons (Ishihara et al., 1999) or in central projections of tauGFP expressing sensory neurons of Drosophila (Williams et al., 2000).

The recent findings of Holzbaur and colleagues demonstrate that tau protein accumulation on microtubules affects anterograde and retrograde transports differently (Dixit et al., 2008). On encountering a tau patch, kinesin falls off the microtubules, whereas dynein switches direction or slows. Whether tau-sapphire GFP fusion protein accumulates aberrantly in NPY-GFP interneurons is as yet unknown, but our tau and GFP immunolabelings in axon swellings were remarkably strong. Therefore, the deleterious effects on morphology and electrophysiological properties observed in this study may be due to an overproduction of tau-GFP. Aberrant accumulation of tau-GFP on microtubules may induce a failure in the axonal transport and cause lysosome accumulation and swelling formation, which probably lead to neurodegeneration. Indeed, transport defects may be associated with malfunction of the degradative compartments, resulting in degeneration (Lim and Kraut, 2009). Impaired axonal transport is one of the earliest manifestations of several neurodegenerative pathologies, such as in Alzheimer disease (Chevalier-Larsen and Holzbaur, 2006; Stokin and Goldstein, 2006).

Another consequence of tau overproduction was also observed in Drosophila nonneuronal cultured cells, in which it can induce round cells to form axon-like protru- sions (Baas et al., 1991; Knops et al., 1991). This observation is of peculiar interest here, insofar as we observed that swellings were located at branching points, where intense and abnormal axonal ramification occurred. This phenomenon suggests a compensatory growth, a phenomenon already observed during neurodegeneration.

In summary, the results of the present study suggest that the expression of a tau-based reporter construct causes severe defects in NPY-GFP interneurons. For this reason, care must be taken when selecting reporter genes for transgenic constructs.

\section{ACKNOWLEDGMENTS}

We thank Prof. J. Friedman for providing the BAC NPY-GFP construct, Marcel Leopoldie for animal care and feeding, Dr. J.M. Heard for providing the antibody raised against Lamp1, Dr. Nicolas Gervasi for his advice on confocal microscopy, and Annick Aubin-Pouliot for making some of the transgenic NPY-GFP interneuron reconstructions.

\section{REFERENCES}

Antonopoulos J, Papadopoulos GC, Michaloudi H, Cavanagh ME, Parnavelas JG. 1992. Postnatal development of neuropeptide Y-containing neurons in the visual cortex of normal- and dark-reared rats. Neurosci Lett 145:75-78.

Ascoli GA, et al. 2008. Petilla terminology: nomenclature of features of GABAergic interneurons of the cerebral cortex. Nat Rev Neurosci 9:557-568

Baas PW, Pienkowski TP, Kosik KS. 1991. Processes induced by tau expression in $\mathrm{Sf} 9$ cells have an axon-like microtubule organization. J Cell Biol 115:1333-1344.

Brand A. 1995. GFP in Drosophila. Trends Genet 11:324-325.

Bridge KE, Berg N, Adalbert R, Babetto E, Dias T, Spillantini MG, Ribchester RR, Coleman MP. 2009. Late onset distal axonal swelling in YFP-H transgenic mice. Neurobiol Aging 30:309-321.

Carnevale NT, Tsai KY, Claiborne BJ, Brown TH. 1997. Comparative electrotonic analysis of three classes of rat hippocampal neurons. J Neurophysiol 78:703-720.

Cataldo AM, Hamilton DJ, Barnett JL, Paskevich PA, Nixon RA. 1996. Properties of the endosomal-lysosomal system in the human central nervous system: disturbances mark most neurons in populations at risk to degenerate in Alzheimer's disease. J Neurosci 16:186-199.

Cauli B, Audinat E, Lambolez B, Angulo MC, Ropert N, Tsuzuki K, Hestrin S, Rossier J. 1997. Molecular and physiological diversity of cortical nonpyramidal cells. J Neurosci 17:3894-3906.

Chandler KJ, Chandler RL, Broeckelmann EM, Hou Y, Southard-Smith EM, Mortlock DP. 2007. Relevance of BAC transgene copy number in mice: transgene copy number variation across multiple transgenic lines and correlations with transgene integrity and expression. Mamm Genome 18:693-708.

Chevalier-Larsen E, Holzbaur EL. 2006. Axonal transport and neurodegenerative disease. Biochim Biophys Acta 1762:1094-1108.

Chudakov DM, Lukyanov S, Lukyanov KA. 2005. Fluorescent proteins as a toolkit for in vivo imaging. Trends Biotechnol 23:605-613.

DeFelipe J. 1993. Neocortical neuronal diversity: chemical heterogeneity revealed by colocalization studies of classic neurotransmitters, neuropeptides, calcium-binding proteins, and cell surface molecules. Cereb Cortex 3:273-289.

Detrait ER, Bowers WJ, Halterman MW, Giuliano RE, Bennice L, Federoff HJ, Richfield EK. 2002. Reporter gene transfer induces apoptosis in primary cortical neurons. Mol Ther 5:723-730. 
Dixit R, Ross JL, Goldman YE, Holzbaur EL. 2008. Differential regulation of dynein and kinesin motor proteins by tau. Science 319:1086-1089.

Dumitriu D, Cossart R, Huang J, Yuste R. 2007. Correlation between axonal morphologies and synaptic input kinetics of interneurons from mouse visual cortex. Cereb Cortex 17:81-91.

Fairen A, De Felipe J, Regiodor J. 1984. Nonpyramidal neurons. In: Peters A, Jones EG, editors. Cereb cortex. New York: Plenum. p 201-253.

Fritze CE, Anderson TR. 2000. Epitope tagging: general method for tracking recombinant proteins. Methods Enzymol 327:3-16.

Giraldo P, Montoliu L. 2001. Size matters: use of YACs, BACs and PACs in transgenic animals. Transgenic Res 10:83-103.

Giraldo P, Rival-Gervier S, Houdebine LM, Montoliu L. 2003. The potential benefits of insulators on heterologous constructs in transgenic animals. Transgenic Res 12:751-755.

Gong S, Zheng C, Doughty ML, Losos K, Didkovsky N, Schambra UB, Nowak NJ, Joyner A, Leblanc G, Hatten ME, Heintz N. 2003. A gene expression atlas of the central nervous system based on bacterial artificial chromosomes. Nature 425:917-925.

Gupta A, Wang Y, Markram H. 2000. Organizing principles for a diversity of GABAergic interneurons and synapses in the neocortex. Science 287:273-278.

Heaney JD, Bronson SK. 2006. Artificial chromosome-based transgenes in the study of genome function. Mamm Genome 17:791-807.

Heintz N. 2001. BAC to the future: the use of bac transgenic mice for neuroscience research. Nat Rev Neurosci 2:861-870.

Hendry SH, Jones EG, Emson PC. 1984. Morphology, distribution, and synaptic relations of somatostatin- and neuropeptide Y-immunoreactive neurons in rat and monkey neocortex. J Neurosci 4:2497-2517.

Henikoff S. 1998. Conspiracy of silence among repeated transgenes. Bioessays 20:532-535.

Ikawa M, Kominami K, Yoshimura Y, Tanaka K, Nishimune Y, Okabe M. 1995. A rapid and non-invasive selection of transgenic embryos before implantation using green fluorescent protein (GFP). FEBS Lett 375:125-128.

Ishihara T, Hong M, Zhang B, Nakagawa Y, Lee MK, Trojanowski JQ, Lee VM. 1999. Age-dependent emergence and progression of a tauopathy in transgenic mice overexpressing the shortest human tau isoform. Neuron 24:751-762.

Jaenisch R. 1988. Transgenic animals. Science 240:1468-1474.

Karagiannis A, Gallopin T, David C, Battaglia D, Geoffroy H, Rossier J, Hillman EM, Staiger JF, Cauli B. 2009. Classification of NPY-expressing neocortical interneurons. J Neurosci 29:3642-3659.

Katayama H, Yamamoto A, Mizushima N, Yoshimori T, Miyawaki A. 2008. GFP-like proteins stably accumulate in lysosomes. Cell Struct Funct 33:1-12.

Kawaguchi Y, Kubota Y. 1997. GABAergic cell subtypes and their synaptic connections in rat frontal cortex. Cereb Cortex 7:476-486.

Klionsky DJ, Emr SD. 2000. Autophagy as a regulated pathway of cellular degradation. Science 290:1717-1721.

Knops J, Kosik KS, Lee G, Pardee JD, Cohen-Gould L, McConlogue L. 1991. Overexpression of tau in a nonneuronal cell induces long cellular processes. J Cell Biol 114:725-733.

Krestel HE, Mihaljevic AL, Hoffman DA, Schneider A. 2004. Neuronal co-expression of EGFP and beta-galactosidase in mice causes neuropathology and premature death. Neurobiol Dis 17:310-318.

Krichmar JL, Nasuto SJ, Scorcioni R, Washington SD, Ascoli GA. 2002. Effects of dendritic morphology on CA3 pyramidal cell electrophysiology: a simulation study. Brain Res 941:11-28.

Krulewski TF, Neumann PE, Gordon JW. 1989. Insertional mutation in a transgenic mouse allelic with Purkinje cell degeneration. Proc Natl Acad Sci U S A 86:3709-3712.

Kubota Y, Hattori R, Yui Y. 1994. Three distinct subpopulations of GABAergic neurons in rat frontal agranular cortex. Brain Res 649:159-173.

Lambolez B, Audinat E, Bochet P, Crepel F, Rossier J. 1992. AMPA receptor subunits expressed by single Purkinje cells. Neuron 9:247-258.
Lim A, Kraut R. 2009. The Drosophila BEACH family protein, blue cheese, links lysosomal axon transport with motor neuron degeneration. J Neurosci 29:951-963.

Mainen ZF, Sejnowski TJ. 1996. Influence of dendritic structure on firing pattern in model neocortical neurons. Nature 382:363-366.

Markram H, Toledo-Rodriguez M, Wang Y, Gupta A, Silberberg G, Wu C. 2004. Interneurons of the neocortical inhibitory system. Nat Rev Neurosci 5:793-807.

McBain CJ, Fisahn A. 2001. Interneurons unbound. Nat Rev Neurosci 2:11-23.

Miklos GL, Rubin GM. 1996. The role of the genome project in determining gene function: insights from model organisms. Cell 86:521-529.

Mizushima N, Ohsumi Y, Yoshimori T. 2002. Autophagosome formation in mammalian cells. Cell Struct Funct 27:421-429.

Nixon RA. 2006. Autophagy in neurodegenerative disease: friend, foe or turncoat? Trends Neurosci 29:528-535.

Nixon RA, Cataldo AM. 2006. Lysosomal system pathways: genes to neurodegeneration in Alzheimer's disease. J Alzheimers Dis 9:277-289.

Pinto S, Roseberry AG, Liu H, Diano S, Shanabrough M, Cai X, Friedman JM, Horvath TL. 2004. Rapid rewiring of arcuate nucleus feeding circuits by leptin. Science 304:110-115.

Poirazi P, Brannon T, Mel BW. 2003. Arithmetic of subthreshold synaptic summation in a model CA1 pyramidal cell. Neuron 37:977-987.

Rachel RA, Wellington SJ, Warburton D, Mason CA, Beermann F. 2002. A new allele of Gli3 and a new mutation, circletail (Crc), resulting from a single transgenic experiment. Genesis 33:55-61.

Roseberry AG, Liu H, Jackson AC, Cai X, Friedman JM. 2004. Neuropeptide $\mathrm{Y}$-mediated inhibition of proopiomelanocortin neurons in the arcuate nucleus shows enhanced desensitization in ob/ob mice. Neuron 41:711-722.

Ross AJ, Waymire KG, Moss JE, Parlow AF, Skinner MK, Russell LD, MacGregor GR. 1998. Testicular degeneration in Bclw-deficient mice. Nat Genet 18:251-256.

Ruano D, Lambolez B, Rossier J, Paternain AV, Lerma J. 1995. Kainate receptor subunits expressed in single cultured hippocampal neurons: molecular and functional variants by RNA editing. Neuron 14:1009-1017.

Rubinsztein DC. 2006. The roles of intracellular protein-degradation pathways in neurodegeneration. Nature 443:780-786.

Schaefer AT, Larkum ME, Sakmann B, Roth A. 2003. Coincidence detection in pyramidal neurons is tuned by their dendritic branching pattern. J Neurophysiol 89:3143-3154.

Shizuya H, Birren B, Kim UJ, Mancino V, Slepak T, Tachiiri Y, Simon M. 1992. Cloning and stable maintenance of 300-kilobase-pair fragments of human DNA in Escherichia coli using an F-factor-based vector. Proc Natl Acad Sci U S A 89:8794-8797.

Stokin GB, Goldstein LS. 2006. Axonal transport and Alzheimer's disease. Annu Rev Biochem 75:607-627.

Wang QJ, Ding Y, Kohtz DS, Mizushima N, Cristea IM, Rout MP, Chait BT, Zhong Y, Heintz N, Yue Z. 2006. Induction of autophagy in axonal dystrophy and degeneration. J Neurosci 26:8057-8068.

Whittington MA, Traub RD. 2003. Interneuron diversity series: inhibitory interneurons and network oscillations in vitro. Trends Neurosci 26:676-682. Williams DW, Tyrer M, Shepherd D. 2000. Tau and tau reporters disrupt central projections of sensory neurons in Drosophila. J Comp Neurol 428:630-640.

Yang XW, Model P, Heintz N. 1997. Homologous recombination based modification in Escherichia coli and germline transmission in transgenic mice of a bacterial artificial chromosome. Nat Biotechnol 15:859-865.

Zhuo L, Sun B, Zhang CL, Fine A, Chiu SY, Messing A. 1997. Live astrocytes visualized by green fluorescent protein in transgenic mice. Dev Biol 187:36-42.

Zomorrodi R, Kröger H, Timofeev I. 2008. Modeling thalamocortical cell: impact of $\mathrm{Ca}$ Channel distribution and cell geometry on firing pattern. Front Comput Neurosci 2:5. 